\title{
Crystallinity, Microstructure and Mechanical Strength of Yttria-Stabilized Tetragonal Zirconia Ceramics for Optical Ferrule
}

\author{
Sung-Dai Kim ${ }^{1}$, Kyu-Seog Hwang ${ }^{2 *}$ \\ ${ }^{1}$ Department of Quality Non-Destructive Testing, Seoul Sanggye Vocational School, Seoul, Korea; ${ }^{2}$ Department of Biomedical En- \\ gineering, Nambu University, Gwangju, Korea. \\ Email: h.silica@gmail.com
}

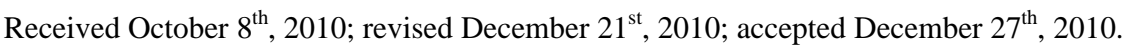

\begin{abstract}
Yttria-stabilized zirconia ceramics were prepared by using different raw materials in order to compare commercially available optical ferrule. Injection-molded cylindrical green compacts were sintered in air at $1350^{\circ} \mathrm{C}, 1400^{\circ} \mathrm{C}$ and $1450^{\circ} \mathrm{C}$ for $2 \mathrm{hrs}$, followed by furnace cooling. Crystallinity, microstructure and mechanical strength of the sintered body were evaluated by using an $X$-ray diffraction analyses, a field emission-scanning electron microscope, a universal tester, and a micro-hardness tester, respectively. For practical usage, the sample B sintered at $1350^{\circ} \mathrm{C}$ was favorable because of high tetragonality and good mechanical strength.
\end{abstract}

Keywords: Zirconia, Tetragonality, Mechanical Strength

\section{Introduction}

It is well known that yttria $\left(\mathrm{Y}_{2} \mathrm{O}_{3}\right)$-stabilized tetragonal zirconia $\left(\mathrm{ZrO}_{2}\right)$ polycrystal ( $\left.\mathrm{Y}-\mathrm{TZP}\right)$ possesses excellent mechanical properties and represents toughened zirconia ceramics [1,2]. The relationship between microstructure and mechanical properties in Y-TZP ceramics has been studied extensively over the past decade [3-5]. Generally, it has been found that Y-TZP ceramics have high strength and fracture toughness, making them attractive candidates for a number of demanding structural applications. It is also well established that these desirable mechanical properties are strongly influenced by grain size. For example, maximum strength is usually achieved with a small grain size $(<1 \mu \mathrm{m})$. Their excellent mechanical properties are derived from the stress-induced martensitic transformation of the metastable tetragonal to the monoclinic phase [6].

The synthesis of fully tetragonal, pure, nano-crystal, uniformly aggregated, agglomerate free zirconia powder is the main emphasis in the production of advanced ceramics with a desirable microstructure and properties. The small grain size of the nanomaterials has a pronounced effect on many physical properties, such as increased strength and hardness.

Throughout our previous work [7], we studied crystal- linity and microstructure of Y-TZP ceramics as a function of the variation of raw materials provided by different suppliers with different particle-properties. From previous results, we confirmed that the raw materials with fine particle size and high tetragonality could be sintered to dense Y-TZP at $1400^{\circ} \mathrm{C}$.

In this work, in order to compare commercially available sample A with two raw materials (denoted B and C), which exhibited relatively good sinterability in our previous work [7], were selected for practical usage. Crystallinity, microstructure and mechanical strength were examined as a function of various sintering temperature.

\section{Experimental}

Yttria-stabilized zirconia (YSZ) powders with composition $97 \mathrm{~mol} \% \mathrm{ZrO}_{2}-3 \mathrm{~mol} \% \mathrm{Y}_{2} \mathrm{O}_{3}$ have been provided by three different suppliers denoted as A, B and C (see Ref. [7]). Green bodies of the Y-TZP were prepared by mixing aqueous binder and YSZ powder at $100 \sim 150^{\circ} \mathrm{C}$ for 24 hrs. After mixing, green compacts were formed with a ferrule ingot using a screw type injection-molding machine. Cylindrical specimens for optical ferrule were sintered in air at atmospheric pressure at $1350^{\circ} \mathrm{C}, 1400^{\circ} \mathrm{C}$ and $1450^{\circ} \mathrm{C}$ for $2 \mathrm{hrs}$, followed by furnace cooling.

Crystallinity of the sintered specimens was determined 
by X-ray diffraction (XRD) (Rigaku Co., D-Max-1200, Jpn.) $\theta-2 \theta$ scans. The XRD patterns were recorded by using $\mathrm{CuK} \alpha$ radiation $(\lambda=1.54056 \AA)$ generated at 40 $\mathrm{kV}$ and $30 \mathrm{~mA}$ in the $20^{\circ}<2 \theta<40^{\circ}$ range. For this purpose the specimens were ground after sintering by agate milling. Tetragonality of the sintered body was calculated from below equation;

$$
T(\%)=I_{\mathrm{t}}(111) / I_{\mathrm{m}}(111)+I_{\mathrm{m}}(-111)+\operatorname{It}(111)
$$

where $I_{\mathrm{m}}(111), I_{\mathrm{m}}(-111)$ and $I_{\mathrm{t}}(111)$ are the intensities of monoclinic (111), monoclinic (-111) and tetragonal (111) reflections, respectively. Surface morphology of the fractured cross-section of the sintered samples was examined by using a field emission-scanning electron microscope (FE-SEM) (Hitachi Co., S-4700, Jpn.). Bending strength and Vickers' hardness were examined by universal tester (Instron 4302, Instron Co., England) and microhardness tester (Shimadzu Co., HMV-2 series, Jpn.), respectively.

\section{Results and Discussion}

Figures 1 and 2 show the XRD patterns for the sintered Y-TZP specimens $B$ and $C$ at various sintering temperatures, as comparing with specimen A sintered at $1400^{\circ} \mathrm{C}$. It could be seen in Figures $\mathbf{1}$ and $\mathbf{2}$ that no other phases except for tetragonal and monoclinic Y-TZP phases were detected by the XRD analysis. As shown in Figure 1,

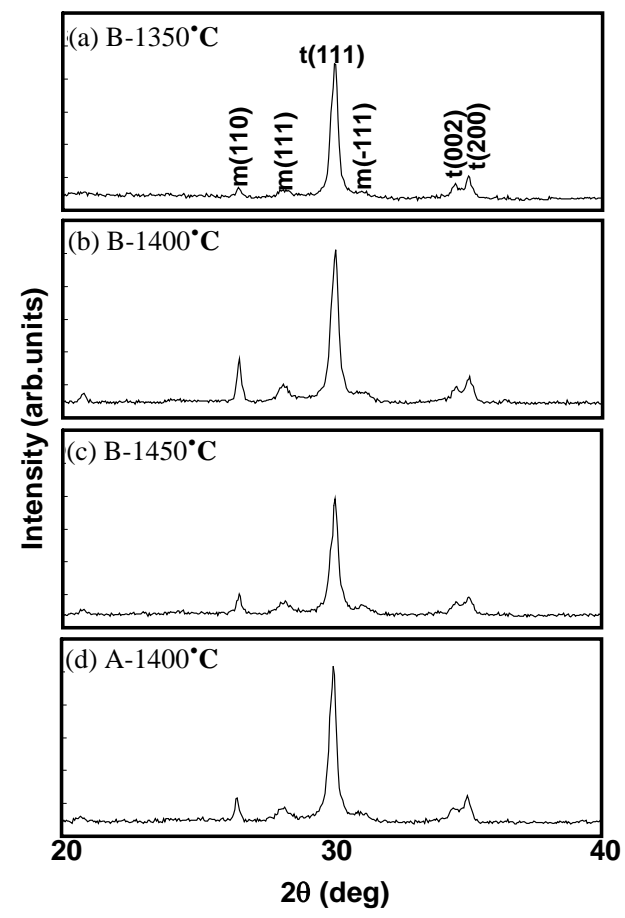

Figure 1. XRD patterns of the specimen $B$ sintered at $1350^{\circ} \mathrm{C}(\mathrm{a})$, at $1400^{\circ} \mathrm{C}(\mathrm{b})$ and at $1450^{\circ} \mathrm{C}$ (c), and the specimen A sintered at $1400^{\circ} \mathrm{C}(\mathrm{d})$.
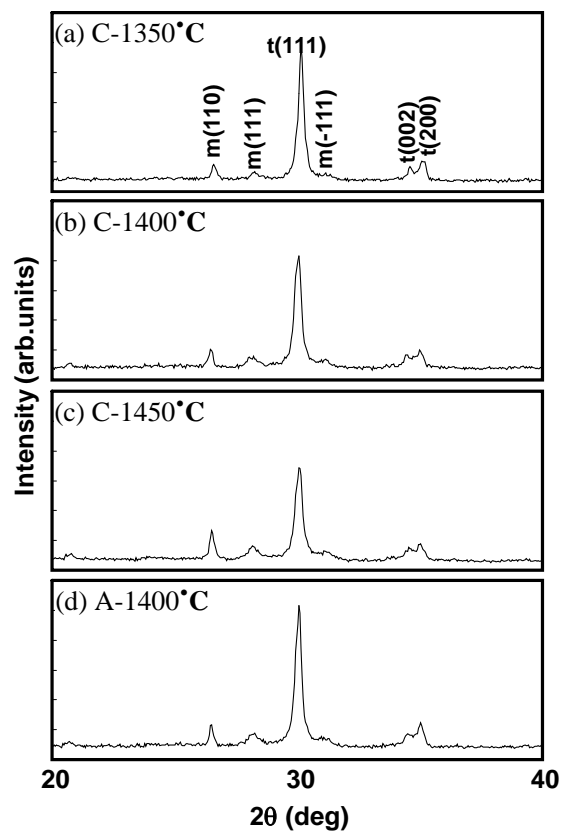

Figure 2. XRD patterns of the specimen $C$ sintered at $1350^{\circ} \mathrm{C}(\mathrm{a})$, at $1400^{\circ} \mathrm{C}(\mathrm{b})$ and at $1450^{\circ} \mathrm{C}$ (c), and the specimen $A$ sintered at $1400^{\circ} \mathrm{C}$ (d).

specimen $\mathrm{B}$ showed the highest intensity of tetragonal (111) reflection at $1400^{\circ} \mathrm{C}$, although, at $1450^{\circ} \mathrm{C}$, crystallinity was gradually decreased. On the contrary, for the specimen $\mathrm{C}$, as the increase of sintering temperature from $1350^{\circ} \mathrm{C}$ to $1450^{\circ} \mathrm{C}$, peak intensity corresponds to tetragonal (111) reflection rather decreased, as shown in Figure 2.

In order to more clearly compare differences of peak intensities between the tetragonal and monoclinic, peak intensities of tetragonal (111), monoclinic (110), monoclinic (111) and monoclinic (-111) were illustrated as shown in Figure 3. As clearly shown in Figure 3, the crystallinities of tetragonal (111) for the specimen B sintered at $1400^{\circ} \mathrm{C}$ and the specimen $\mathrm{C}$ sintered at $1350^{\circ} \mathrm{C}$ exhibited higher intensities than those of other samples. However, although tetragonal peak intensity of specimen B sintered at $1400^{\circ} \mathrm{C}$ was comparable to that of specimen A sintered at $1400^{\circ} \mathrm{C}$, which showed a dense and compact microstructure in previous work [7], its peak intensities of monoclinic reflections, especially (110), exhibited much higher values than those of other samples.

In order to compare crystalline structure, we illustrated change of tetragonality for the sintered specimens. As shown in Figure 4, all the specimens, except specimen C sintered at $1450^{\circ} \mathrm{C}$, showed high tetragonality after sintering, i.e., above $70 \%$. However, for the specimens B and $\mathrm{C}$, tetragonality was decreased as the increase with sintering temperature from $1350^{\circ} \mathrm{C}$ to $1450^{\circ} \mathrm{C}$. We assume that low-temperature sintering was effective to increase tetragonality of specimens B and C. The highest 


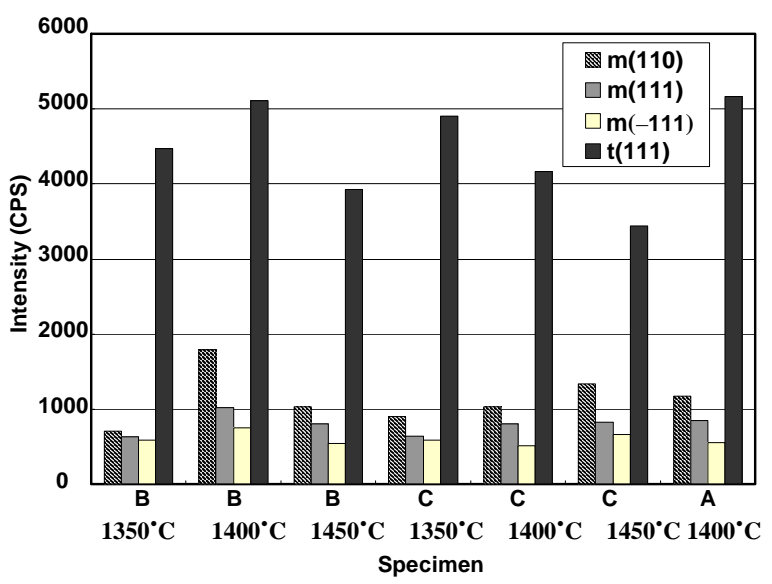

Figure 3. XRD peak intensities of tetragonal or monoclinic reflections [m(110): Monoclinic (110), m(111): Monoclinic (111), m(-111): Monoclinic (-111) and t(111): Tetragonal (111)].

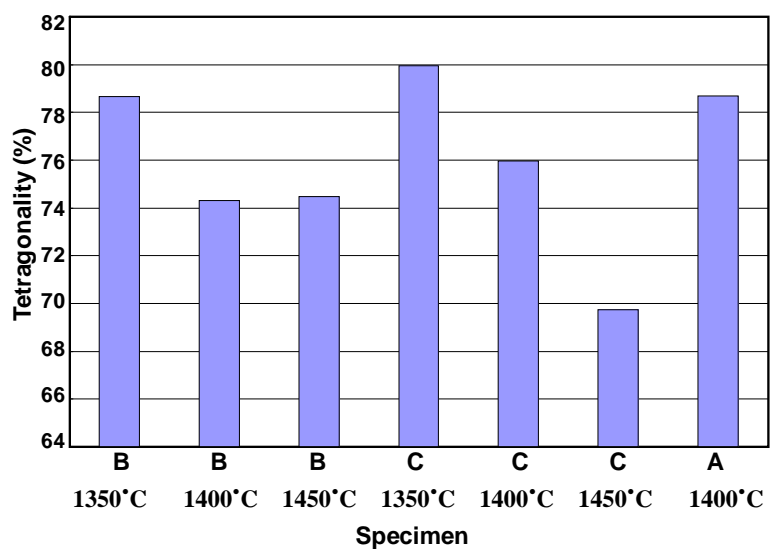

Figure 4. Variation of tetragonality of specimens at various sintering temperatures.

tetragonality about $79.95 \%$ was obtained from the specimen $\mathrm{C}$ after sintering at $1350^{\circ} \mathrm{C}$.

Figures 5 and 6 show the FE-SEM images of fractured cross section of the sintered specimens. As clearly shown in Figure 6, all the specimens had well-crystallized grains with $0.2 \sim 0.4 \mu \mathrm{m}$ in size. Break down was concurrently occurred at the inside and at the interface of the grains for all the specimens. However, for the specimen $\mathrm{C}$, some pores were found as shown in Figures 5(d-f).

Figure 7 shows the bending strength of the specimens. The highest bending strength was obtained for the standard sample A. Specimen C, which possessed some pores as shown in Figures 5(d-f), exhibited low bending strength, while the specimen B performed relatively high bending strength. Low bending strength of the specimen $\mathrm{C}$ was quite reasonable, since observable pores probably corresponding to weak mechanical strength were recog-
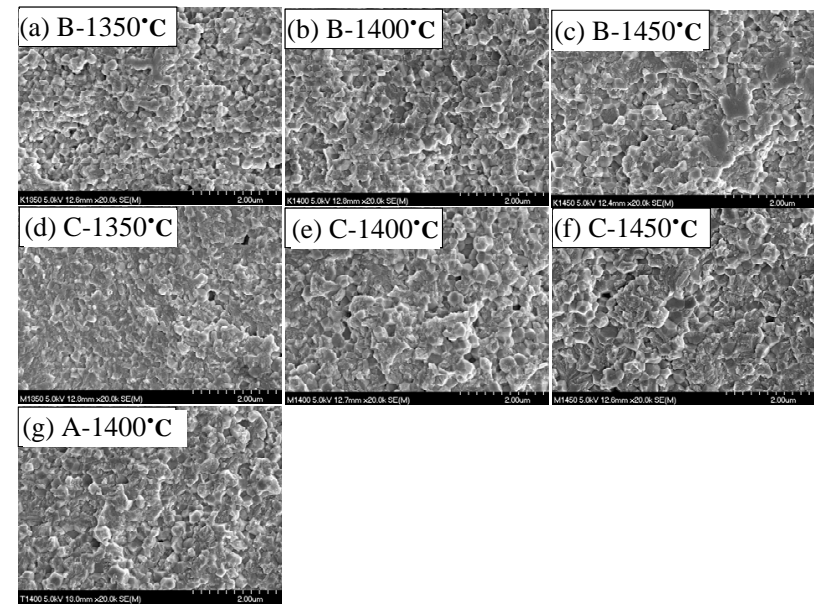

Figure 5. FE-SEM images of fractured cross section of the specimens $(\times 20,000)$.

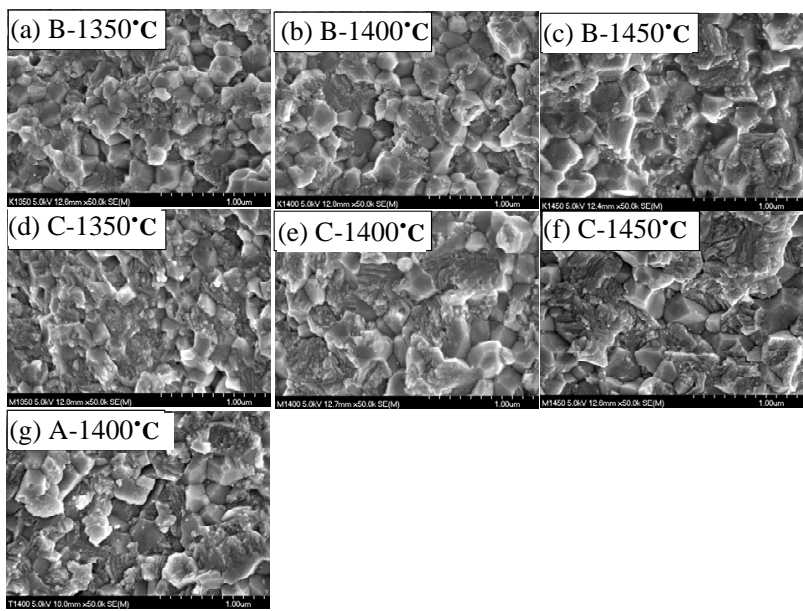

Figure 6. FE-SEM images of fractured cross section of the specimens $(\times 50,000)$.

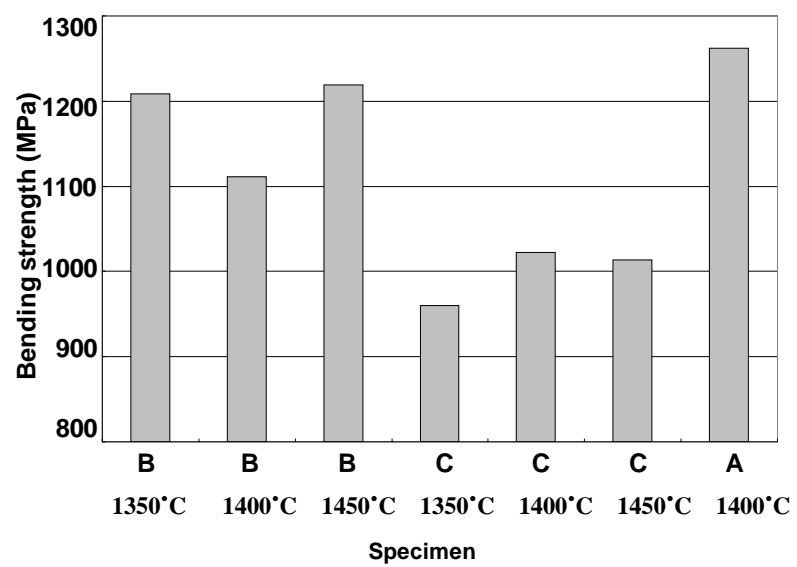

Figure 7. Bending strength of the specimens at various sintering temperatures. 
nized in sintered body, as shown in Figure 5.

Vickers' hardness is plotted as Figure 8. It is found that specimen $\mathrm{B}$ sintered at $1350^{\circ} \mathrm{C}$ and specimen $\mathrm{C}$ sintered at $1450^{\circ} \mathrm{C}$ showed higher values. It should be pointed out in this work that, for the specimen $\mathrm{C}$, some unclear problems, such as pores in sintered body and low bending strength, were still existed, although their hardness above $\sim 1200$ was sufficient for practical usage to optical ferrule. Furthermore, for the specimen B, hardness was rather lowered by high-temperature sintering. We assume that hardness was probably decreased by existence of some amorphous-like phases in appearance, as shown in Figure 5(c). Conclusively speaking, for the specimen B, low-temperature sintering was favorable for the sintered body with high tetragonality and good mechanical properties.

Figure 9 shows surface morphology (a) and photograph (b) of prepared optical ferrule annealed at $1350^{\circ} \mathrm{C}$ by using raw material B. As shown in Figure 9(a), well-defined small grains with below $\sim 1 \mu$ m were densely formed. For our specimen B, it is difficult to find pores after sintering, which generally exhibited at the grain or at the grain boundary of sintered zirconia specimens. A smooth specimen surface was obtained by polishing the scratches.

\section{Conclusions}

In this work, two raw materials (B and C), which exhibited relatively good sinterability in our previous work were selected in order to compare with commercially available sample A. Low-temperature sintering was effective to increase tetragonality of the specimens B and C. For all the specimens, microstructures contained wellcrystallized grains with $0.2 \sim 0.4 \mu \mathrm{m}$ in size were characterized by FE-SEM. For practical usage, characterized by FE-SEM. For practical usage, low-temperature sinter-

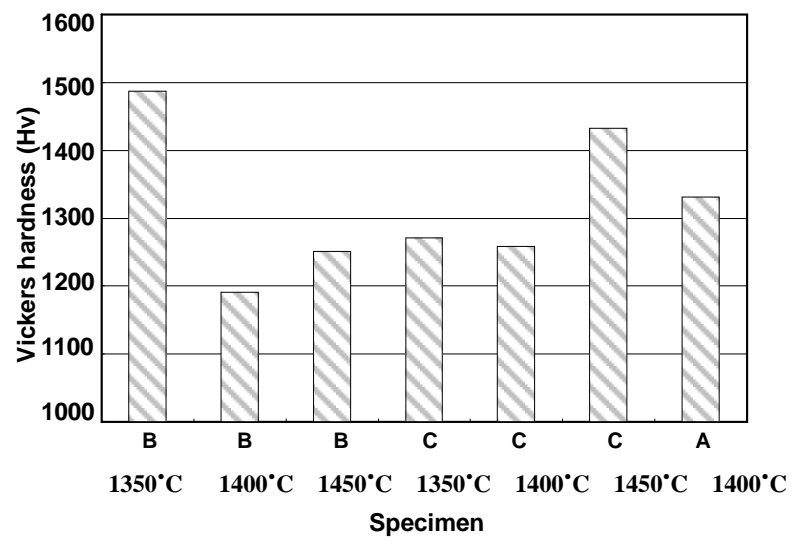

Figure 8. Vickers' hardness of the specimens at various sintering temperatures.
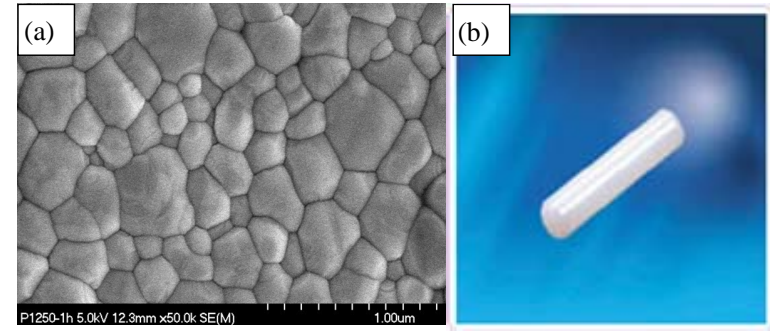

Figure 9. Surface morphology (a) and photograph (b) of prepared optical ferrule sintered at $1350^{\circ} \mathrm{C}$ by using raw material B.

ing at $1350^{\circ} \mathrm{C}$ was favorable for the specimen $\mathrm{B}$ because of high tetragonality and mechanical strength. While, for the specimen $\mathrm{C}$, some unsoluble problems, such as pores in the sintered body and low bending strength, was still occurred.

\section{REFERENCES}

[1] J. M. Wu and C. H. Wu, "Sintering Behaviour of Highly Agglomerated Ultrafine Zirconia Powders," Journal of Materials Science, Vol. 23, No. 9, September 1998, pp. 3290-3299. doi:10.1007/BF00551308

[2] T. Kubo, K. Ichikawa, N. Machida, H. Sakai and T. Shigematsu, "Effect of Calcining Temperature on the Tetragonal-to-Monoclinic Phase Transition Characteristics in 2 mol\% Yittria-Doped Zirconia Ceramics,” Journal Materials Science, Vol. 35, No. 12, June 2000, pp. 3053 $-3057$. doi:10.1023/A:1004803532387

[3] Y. Zhang, A. Pajares and B. R. Lawn, "Fatigue and Damage Tolerance of Y-TZP Ceramics in Layered Biomechanical Systems," Journal of Biomedical Materials Research B: Applled Biomaterials, Vol. 71B, October 2004, pp. 166-171.

[4] D. R. R. Lazar, M. C. Bottino, M. Ozcanc, L. F. Valandro, R. Amaral, V. Ussui and A. H. A. Bressiani, "Y-TZP Ceramic Processing from Coprecipitated Powders: A Comparative Study with Three Commercial Dental Ceramics," Dental Materials, Vol. 24, No. 12, April 2008, pp. 16761685.

doi:10.1016/j.dental.2008.04.002

[5] S.-J. Ha, B.-C. Shin, M.-W. Choi, K.-J. Lee and W.-S. Cho, "High Speed End-Milling Characteristics of PreSintered $\mathrm{Al}_{2} \mathrm{O}_{3} / \mathrm{Y}$-TZP Ceramic Composites for Dental Applications," Journal of the Ceramic Society of Japan, Vol. 118, No. 1383, November 2010, pp. 1053-1056. doi:10.2109/jcersj2.118.1053

[6] Y. Kitano, Y. Mori, and A. Ishitani, "Structural Changes by Mechanical and Thermal Stresses of 2.5-mol\%- $\mathrm{Y}_{2} \mathrm{O}_{3}$ Stabilized Tetragonal $\mathrm{ZrO}_{2}$ Polycrystals," Journal of American Ceramic Society, Vol. 71, No. 8, August 1988, pp. C-382-C-383. 
doi:10.1111/j.1151-2916.1988.tb06399.X

[7] S.-H. Yang, S.-B. Kim, B.-A. Kang, Y.-H. Yun, Y.-H. Kim and K.-S. Hwang, "Preparation of Yttria-Stabilized Tetragonal Zirconia Ceramics for Optical Ferrule,” Jour- nal of Materials Synthesis \& Processing, Vol. 9, No. 5, September 2001, pp. 275-279. doi:10.1023/A:1015203602403 